\title{
Live Streaming - the New Era of Online Shopping
}

\section{Qiaowen Chen ${ }^{1, *}$}

\author{
${ }^{1}$ Questrom School of Business, Boston University \\ Boston, MA, United States, 02215 \\ *cqwash@bu.edu
}

\begin{abstract}
Livestream shopping was first introduced in 2016 and become a novel industry worth more than billions of dollars in just 5 years. This rapid development is contributed by the rising number of live hosts joining the industry and the active customers who would be spending more on stock up and leisure goods. To decode the reason behind the explosive growth of the industry, we need to see how Livestream shopping is creating value for both hosts and customers. The diversified hosting style is also playing an important role in the formation of the hosts' community. The revenue generated by the hosts has clearly depicted the customer purchase habit and preferences. As a rising industry, Livestream shopping is growing at an uncontrollable speed, which requires the government to pay more attention to the environment clearance and rectify the industry regulation. Given the hard times during the COVID, all parties have grabbed the chance of making e-commerce easier and bringing the industry to another level. By tracing back the origin of the Livestream shopping and analyzing real-life hosts examples like Viya, it enables us to associate the success of Livestream shopping with its outstanding start point and the corresponding counterpart of customers' needs and industry offerings. The analysis reveals the key focus of Livestream shopping sticking to diversity and costeffectiveness. Hosts and suppliers need to strive for competency to win more customer flow and let them make a direct purchase during their shopping journey. While the government also plays an important role in regulating and supporting the development of the live shopping market.
\end{abstract}

Keywords: Livestream shopping, E-commerce, Big data, Online shopping

\section{INTRODUCTION}

When companies are still exploring the future expansion of virtual reality, live streaming has taken one step ahead to earn a position in the melting pot of online shopping. In 2020, the global live streaming market reached a value of over USD 50 billion and is expected to grow at a CAGR of more than $20 \%$ in the following decade. [1] The combination of Livestream with commerce was first introduced by Alibaba's Taobao in 2016. In less than half a decade, this industry giant brought this transformation to China's online shopping platforms, and then to the world. In January 2020, when the Chinese were staying at home looking forward to celebrating the Spring Festival, Covid-19 has hit the world and people were required to stay indoors for quarantine. It is during this time when people have more time to get to know this new form of shopping. Still, it is surprising how this entirely new form of shopping can be accepted by the majority in such a short period and generate explosive revenue. Also, seeing the appreciable prospect of Livestream commerce, more people, including celebrities, have stepped into this industry. Customers are also accumulating experience by watching lives and shopping at the same time. By looking back at the path Livestream commerce has gone through over the last few years, analyzing the financial data it has generated and hearing the voice from different parties engaged in this new play, we are able to take a deeper glance at this newly born industry. We can also know the advantage of Livestream commerce compared to other forms of shopping, see the future trend and possible breakthroughs, as well as the potential risks it might face.

\section{ANALYSIS}

\subsection{The Break Out}

Taobao Live, the first online Livestream shopping platform, was introduced in April 2016. This idea came up by a product manager of Alibaba who would love to make e-commerce more like in-store shopping. 
Different from personal online shopping, the keywords of in-store shopping are engagement and communication. Livestream makes up the blank side of online browsing and aiming to provide more details for customers and transforms traditional 2-D online shopping into a multi-dimension experience.

The first live channels in Taobao focus on female clothing. It seems to be an alternative for virtual reality at the moment, but then suppliers and customers found it more direct and distinct. Different models wear different sizes or colors of clothing to provide customers with clear references about the product which helps them saving time and energy in making the final decision. With clothing leading the stream, various products were involved and taken a place in the channels. The jewelry product would be another sign. In the traditional online shopping scenario, the display of the jewelry can be extremely hard. The high price associated with several 2-D online photos would not be enough to convince the customers to make a purchase. Customers become more alert when it comes to online shopping without a material object, not to mention the high price. However, when it comes to living streaming, it developed clear visualization of the jewelries to the customers, along with the detailed introduction from the hosts, customers would be more reassuring and secure to make the purchase.

Later on, cosmetics channels reached its first explosion in March 2019, while foods, hygiene, and electronics peaked in October 2019 when the Single's Day event was about to come. [2] The success of Taobao Live doesn't happen overnight. After the first few years of groping in the dark, the product managers

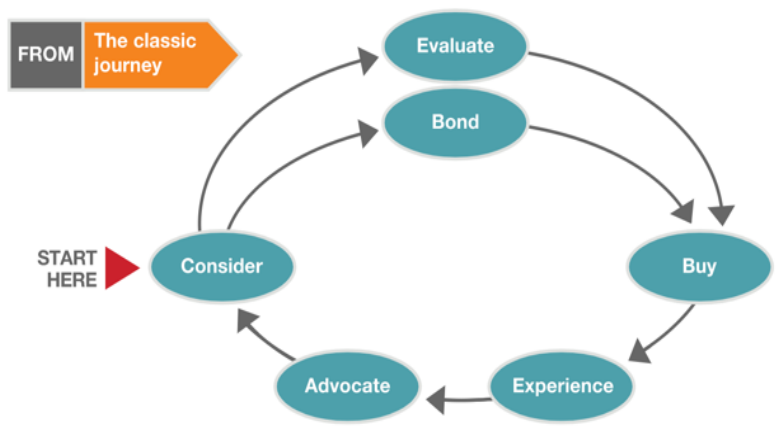

and suppliers have discovered this interactive and immersive way of shopping. The intention of leveraging customers' shopping experience would never benefit only one group of people.

\subsection{A Win-Win Purchase}

Live streaming makes each purchase a win-win for both companies (retailers) and customers. In a classic journey of customer decision, the buyer usually starts with 'considering' the actual needs of buying a particular product to complete the entire decision-making process. Thus, they held the upper hand in the case of purchase situation. The Livestream becomes the booster to reverse this situation by leading the customers directly to the products and let them 'buy' even without "considering" or "evaluating". [3] It leaves little chance for customers to compare between different brands as the products on the shelf are usually of high reputation and can be out of stock in seconds. Contributed to the endowment effect, in which individuals may value an owned object higher than its market value, customers would never want to miss a good deal. Otherwise, they might feel they lost more if they didn't purchase the product. Another reason which stimulates customers' demand is the bundle sale. For consumable products like snacks and hygiene, suppliers will offer bundle discounts like "original price for the 1 st piece, $50 \%$ off for the 2 nd and the 3 rd for free" to attract buyers to purchase more units. This accelerated journey will help the company earn more exposure in front of the crowd and if the products on the shelf coincidently meet the potential need of the customers, they are able to generate more sales.

To

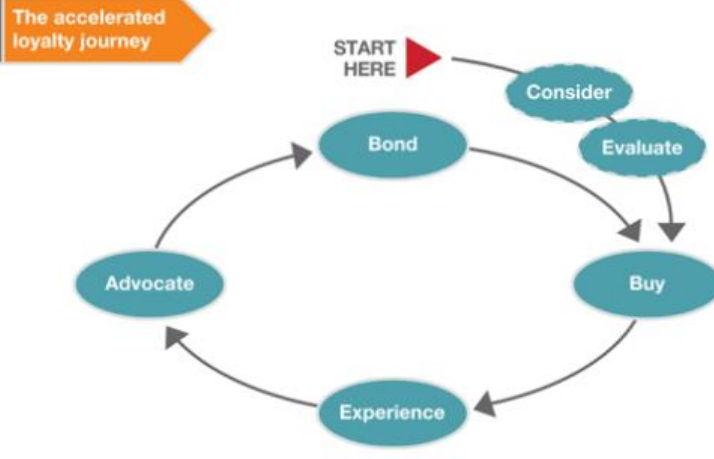

Figure 1 The Transformation from the classic journey to the accelerated loyalty journey [3]

Live streaming, as for customers, seem to be an experience of impulsive consumption. It is easy to attract customers to make a purchase at a low price for the first time, but there are hundreds of different channels out there waiting for customers to join and they will all offer decent deals. Except for developing new customers, increasing the customers' retainment rate becomes another important topic. The key factor of keeping the customers staying in the same channel is engagement. Other than the low price or coupon sale, random red pockets and instant killing products are both ways to retain the customers. Random red pockets can either be given out by the hosts or the suppliers, and the system will select a particular amount of people (e.g., 10 or 20) to divide an amount of money. Instant killing products are more engaging to customers. The hosts will notice the customers that they will release an instant killing product in a second and customers should 
be ready to rush for the product. These products will only cost 1 cent and stocks are very limited. Thus, customers will wait in front of the screen for the product information to pop up, and whoever makes the purchase first just wins the deal.

Both hosts and suppliers are coming up with more deals to keep the audience stay in the channel and attract them to make the purchase. Instead of making an issue on the products, the viral trend of inviting celebrity spokesperson to the live channel is now another way to boost sales.

\subsection{The Star Effect}

In the Chinese mainstream live shopping channels, there are three typical types of hosts. Noted professional hosts like Viya and Li Jiaqi is currently the leading force of the Taobao platform. Every day, they will start their Livestream at around $7 \mathrm{pm}$ and release dozens of different types of products on sale. Contributed by their mature hosting style and abundant subscription base, these hosts have a group of loyal customers, as well as suppliers. In October 2020, Viya set a new record of USD 49.7 million on the presell night of the Single's Day festival. [4] From time to time, suppliers will also invite their brand spokesperson to the channel, which becomes a new way of celebrity endorsement. This type of cooperation also intersects with the "fan economy". In 2020, the Chinese fan market is expected to reach RMB 100 billion (around USD 15.4 billion) with a CAGR of $60 \%$. [5] The blend of these two novelties brings more opportunities to suppliers to revise and advance their marketing tactics.

Other than the brand spokesperson who was invited to the channel one time or two, some influencers and celebrities have created their own Livestream channels. Influencers, (also called KOL or key opinion leaders) become the most important group in interacting with the rest of the community. Usually before setting up a live stream account, they have already had a group of loyal fans that would take their recommendation. In 2019, when Amazon launched their Livestream shopping platform - Amazon Live, the big-name movie star Jessica Alba was brought to headline this new shopping experience. Compared to professional hosts, celebrities don't usually have enough experience of controlling the whole procedure, but contributed to their personal reputation and popularity, there are still a great number of customers willing to purchase their products.

The third type of hosts are suppliers themselves. More online brand stores are currently opening their own channels via Livestream. Compared to hosts who sell collective products, the advantage of self-channel is relatively competitive. The brand hosts can introduce their products at their own pace and leave customers with more time to ask and evaluate. Therefore, suppliers have more intense engagement with customers, and provide potential buyers with more detailed information about brands and products.

All three types of hosts come up with strengths and weaknesses, and they form up the current structure of the Livestream host community. However, as more and more Internet celebrities are transforming from video making to Livestream, with the insufficient knowledge and misunderstanding of this job has brought serious challenges to the industry which also induced the crisis of customer trust.

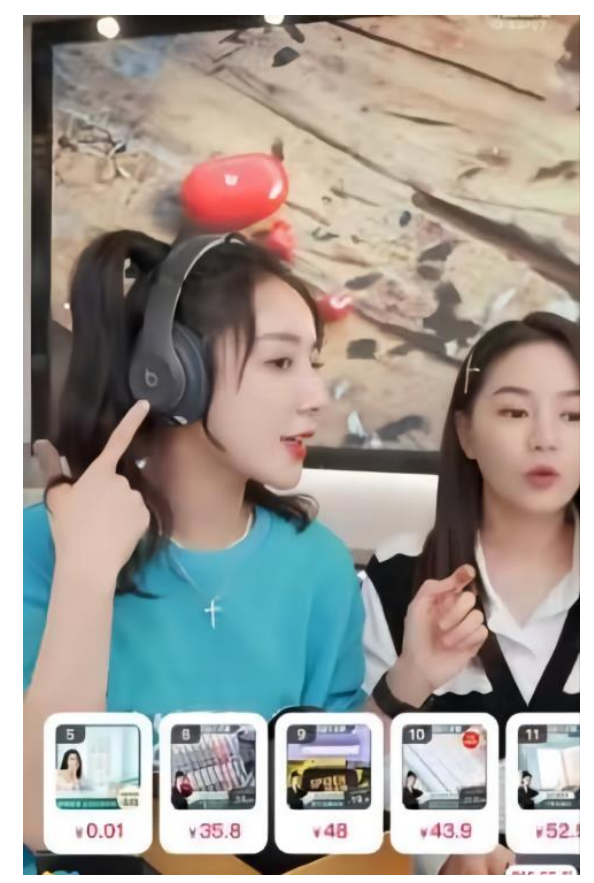

Figure 2 Viya's Taobao Livestream introducing Beats product with a peak view of over 20 million

\section{REGULATION AND CLEARANCE}

While the Livestream industry is developing rapidly, it masked the negative side of the experience to some extent. Fake products, unqualified product control, false marketing are all complaints from the customers and risky factors that might influence the bigger picture. To lower the price of the products, some hosts or suppliers may adulterate unqualified materials to save the cost. Customers, who don't have too much experience in online shopping, will be falsely lured by the hosts and make an unfair purchase. These actions were not carefully monitored by the government in the first few years. However, more detailed and stricter regulations are coming up, and disclosure is also using for supervision to defend the rights and interests of customers.

In November 2021, the live streaming 'sales king', Xinba on Kuaishou, was reported to sell fake bird's nests to over 50,000 customers with revenue of over 15 
million RMB (around USD 2.3 million) [6]. The report shows that the so-called 'bird's nests' is just a bowl of regular syrup and has nothing to do with health maintenance or beauty treatments. In December, the local market supervision bureau has involved and Xinba was fined three times the revenue generated. The aim of government departments is to protect the rights of the customers and maintain a healthy industry atmosphere, but their job is never limited to the downside of the market.

Other than regular surveillance of the market, government departments are also responsible for creating business opportunities and guiding the right direction. During the COVID pandemic, suppliers and factories in many regions of China were forced to stop production and sales activities at that time. Local governments took the lead in launching the "antiepidemic special program" to help suppliers solve inventory problems by using Livestream. This action not only helps the suppliers dispose of the products reasonably and recover the cost but also provides customers with high-quality products at extremely low prices. At the same time, it also expanded the market scale for Livestream. Similar periodic programs became popular on all platforms, and all the servers are coming up with better themes to attract customers.

\section{CONCLUSION}

Livestream shopping is currently at its best age. Companies were given a chance to connect their customers with less effort. Customers enjoy and are willing to learn more about this new type of shopping. This newly born shopping tactic has been digested by the industry naturally in a very short time. Selling tactics including bundling, discount and advertising have all been injected into the procedure. Hosts have earned more clicks and customers have also benefited from the low sale price. But looking at the industry from another dimension, it is not always about roses. A Negative voice can be heard about the products sold and the industry. The lack of inspection provided no place for customers to speak up. Thus, to lengthen the existence of Livestream and improve the healthy ecommerce environment, both customers and the hosts need to comply with the current introduced regulations. Only with this counterbalance relationship, Livestream shopping can create more possibilities between hosts and customers. This essay has a major focus on the development of live stream shopping over the past five years, but there is little information regarding the future trend as well as the projected market size it could reach. In the following studies, more attention could be devoted to predicting the future live stream industry about its changes and possible revolutions.

\section{REFERENCES}

[1] Video streaming market size \& Share report, 2021 2028. Video Streaming Market Size \& Share Report, 2021-2028. (n.d.). https://www.grandviewresearch.com/industryanalysis/video-streaming-market.

[2] Hallanan, L. (2020, November 16). Live streaming Drives \$6 Billion usd in sales during The 11.11 Global Shopping Festival. Forbes. https://www.forbes.com/sites/laurenhallanan/2020/ 11/16/live-streaming-drives-6-billion-usd-in-salesduring-the-1111-global-shoppingfestival/?sh=1103450b21e5.

[3] Edelman, D., \& Singer, M. (2018, February 5). The new consumer decision journey. McKinsey \& Company. https://www.mckinsey.com/businessfunctions/marketing-and-sales/our-insights/thenew-consumer-decision-journey.

[4] Yorke, C. (2021, May 26). How Li JIAQI and Viya became the king and Queen of China's Booming Livestream industry. RADII. https://radiichina.com/li-jiaqi-viya/.

[5] China's Idol Economy: How the Chinese fan culture is SHAPING entertainment and marketing. Daxue Consulting Market Research China. (2021, June 4). https://daxueconsulting.com/china-idol-economy/.

[6] Deng, I. (2021, March 28). Disgraced live-streaming 'SALES king' pulls in US\$300 million in 12 hours. South China Morning Post. https://www.scmp.com/tech/bigtech/article/3127332/comeback-king-chinasdisgraced-live-streaming-sales-king-sells-12. 